Jurnal Agroteknologi, Vol. 9 No. 2, Februari $2019: 6-11$

\title{
PENGGUNAAN ATRAKTAN DAUN TALAS DENGAN VARIASI PESTISIDA NABATI TERHADAP POPULASI KEONG MAS (Mollusca : Ampullariidae) PADA PADI DI SUMATERA UTARA
}

(The Use of Talas Leaf Attractant Using Biopesticide Variation on Population of Pomacea canaliculata
(Mollusca: Ampullariidae) in Paddy Plantation in North of Sumatera)

\author{
VORLY NADEAK, AMEILIA ZULIYANTI SIREGAR* \\ Program Studi Agroekoteknologi, Fakultas Pertanian \\ Universitas Sumatera Utara \\ *Email: azsyanti@gmail.com HP : 082273017027
}

\begin{abstract}
The golden apple snail (Pomacea canaliculata Lamarck) is one of the dominance pests in paddy plantation always found until now, which can not be controlled well due with very fast reproduction. Control with chemical molluscicides leaves an environmental residue, so it is necessary to look for environmentally friendly control alternatives, one of step used by using attractans. This study aims to obtain an effective plant as a biopesticide that can be used to control the golden apple snail in the field. The research was conducted from April to May 2017 in Susuk VIII, Padang Bulan, Medan Selayang. The method used was a complete non factorial randomized design was used consisted of 6 treatments namely control, Areca nut powder (Areca catechu), lemongrass powder (Cymbopogon citrates), Breadfruit leaf powder (Artocarpus altilis), Mengkudu powder (Morinda citrifolia), and water hyacinth powder (Eichhornia crassipes). The results showed the most effective in controlling the mortality of the golden apple snail recorded on the 7th day (100\%) used by the areca powder (Areca catechu). The lowest percentage of clumps of rice attacked by golden apple snail used by betel powder with an average of 0.062 on the death time 2 days after application. The results showed variations of biopesticides can control the golden apple snail on rice plants in Northern Sumatera.
\end{abstract}

Keywords : Colocasia esculenta, Pomacea canaliculata, molecicide of plantation, atractant.

\section{PENDAHULUAN}

Padi merupakan tanaman pangan penting kedua di dunia, yang digunakan sebagai sumber bahan pangan setelah gandum, dan diperkirakan kebutuhannya akan meningkat $70 \%$ pada dekade mendatang (Utama et.al., 2009). Produksi padi pada tahun 2014 sebesar 3,63 ton gabah kering iling, turun sebesar 96.210 ton dibanding produksi padi tahun 2013. Penurunan produksi padi pada tahun 2014 sebesar 96.210 ton $(2,58 \%)$ terjadi pada Mei - Agustus sebesar 89.305 ton $(7,93 \%)$ dan September - Desember sebesar 25.218 ton $(2,30 \%)$ sedangkan pada Januari April produksi naik sebesar 18.313 ton $(1,22 \%)$ dibandingkan dengan produksi pada tahun 2013 (BPS Sumatera Utara, 2015).

Serangan hama dominan diidentifikasi pada tanaman padi dipengaruhi oleh serangan hama keong mas Pomacea canaliculata L. Kerusakan karena serangan keong mas terjadi ketika tanaman masih muda. Akibatnya petani harus menyulam atau menanam ulang pada daerah dengan populasi keong yang tinggi sehingga biaya produksi meningkat (Roja, 2009). Sampai saat ini, diasumsikan tidak ada varietas padi yang tahan terhadap serangan hama keong mas (Hutasoit, 2012; Ng dan Tan, 2011). Untuk mengatasi masalah tersebut maka diperlukan cara pengendalian yang dapat dilakukan dengan konsep Pengendalian hama Terpadu (PHT).

Beberapa penelitian menunjukkan pengendalian keong mas dapat dilakukan dengan berbagai cara. Pengendalian mengontrol hama keongmas dapat dilakuakn secara mekanik, biologis dan kimiawi. Pengendalian yang dapat dilakukan adalah (1) pengendalian secara mekanis dengan memperhatikan pengolahan tanah, membuat saringan pada saluran masuk dan keluar air, dan mengutip secara langsung telur maupun keong mas. (2) pengendalian secara kultur teknis dengan memperhatikan bibit yang digunakan dan penggunaan pupuk dasar. (3) pengendalian secara biologi dengan menggunakan mina padi, penggembalaan 
bebek atau penggunaan predator keong mas dan penggunaan pestisida nabati. (4) pengendalian dengan pestisida kimiawi/sintetik dengan menggunakan bahan kimia berbahan aktif niklosamida (Suharto dan Kurniawati, 2009).

Penggunaaan bahan kimia atau moluskisida sintetis dapat menimbulkan efek samping, seperti resistensi dan resurjensi hama dan pencemaran lingkungan. Oleh karena itu, perlu dicari teknologi yang dapat menekan perkembangan hama yang ramah lingkungan seperti penggunaan pestisida nabati. Pestisida nabati adalah pestisida yang bahan dasarnya bersumber dari tumbuhtumbuhan, seperti akar, daun, batang atau buahnya. Bahan kimia yang terkandung di dalam tumbuhan memiliki bioaktivitas terhadap serangga, seperti bahan penolak atau repellent, penghambat makan atau antifeedant, penghambat perkembangan serangga atau insect growth regulator, dan penghambat peneluran atau oviposition deterrent (Trisnadi, 2016).

Beberapa penelitian dalam pengendalian keberadaan keong mas yang dilakukan menggunakan pestisida nabati, seperti: penggunaan Pinang, serai, sukun, mengkudu, dan eceng gondok, dimana Laoh et al. (2013) melaporkan aplikasi tepung biji pinang telah mampu menyebabkan mortalitas hama keong emas sampai $87,49 \%$. Manakala Budiarsih (2011) melaporkan kandungan senyawa serai yang paling besar adalah sitronela yaitu sebesar 35\%. Senyawa sitronela mempunyai sifat racun kontak yang dapat mengakibatkan kematian karena kehilangan cairan terus menerus.

Francis et al. (2002) melaporkan daun sukun juga mengandung saponin dan beberapa golongan senyawa seperti flavonoid, steroid, tanin, serta phenol. Senyawa saponin dapat mengganggu sistem biologi keong mas dan membunuh menyebutkan bahwa mengkudu mengandung minyak atsiri, alkaloid, saponin, flavonoid, polifenol dan antrakuinon. Selanjutnya Mursito (2002). Senyawa flavonoid dan saponin dapat menimbulkan kelayuan pada saraf serta kerusakan selama 1 minggu pada spirakel yang mengakibatkan serangga tidak bisa bernafas dan akhirnya mati. Johnly dan Suryanto (2010), telah melakukan penelitian untuk menentukan kandungan fenolik, flavonoid, dan tanin pada eceng gondok. Berdasarkan uraian tersebut, peneliti tertarik untuk meneliti beberapa pestisida nabati yang dapat digunakan untuk mengendalikan keong mas pada tanaman padi di lahan Susuk VIII Padang Bulan, Medan Selayang.

\section{BAHAN DAN METODE}

Penelitian ini telah dilaksanakan di Lahan Susuk VIII, Padang Bulan, Medan Selayang, dengan ketinggiaan tempat $\pm 1,5 \mathrm{~m}$ dpl pada bulan April sampai Mei 2017. Bahan yang digunakan adalah buah pinang, serai, daun sukun, buah mengkudu, eceng gondok, benih padi, keong mas, tali rapia, dan plastik. Adapun alat yang digunakan adalah timbangan, blender, meteran, cangkul, saringan, kamera dan alat tulis.

Penelitian ini menggunakan rancangan acak lengkap (RAL) non faktorial dengan perlakuan sebagai berikut : PO : daun talas 500gr (kontrol); P1 : ekstrak pinang $100 \mathrm{gr}+$ daun talas 500gr; P2 : serbuk serai $100 \mathrm{gr}+$ daun talas 500gr; P3 : serbuk daun sukun 100 gr + daun talas 500gr; P4 : serbuk buah mengkudu $100 \mathrm{gr}+$ daun talas 500gr; P5 : serbuk eceng gondok + daun talas $500 \mathrm{gr}$.

\section{Pembuatan Moluskisida Nabati}

Pinang yang di gunakan bagian inti endosperm pinang. Pinang dan buah mengkudu dicuci dengan air dan dijemur mengurangi kadar air kemudian diblender hingga menjadi serbuk kemudian disaring dengan ayakan tepung. Bagian serai yang digunakan adalah bagian batang, kemudian dipotong-potong dan dikeringkan selama 1 minggu kemudian diblender hingga menjadi serbuk kemudian disaring dengan ayakan tepung. Daun sukun dan daun eceng gondok yang di gunakan adalah daun yang tidak terlalu tua juga tidak terlalu muda dicuci dengan air dan dijemur selama 1 minggu untuk mengurangi kadar air kemudian diblender hingga menjadi serbuk dan disaring dengan ayakan tepung. Lahan yang digunakan seluas 400 m2 diolah dan digemburkan, kemudian dibentuk petakan-petakan lahan sesuai jumlah perlakuan.

\section{Inokulasi Keong Mas}

Keong mas dikumpulkan dari lapangan kemudian diinkubasi selama satu minggu dan diberi makan daun talas 2 kali sehari. Keong mas yang digunakan adalah keong mas fase dewasa yang sehat berukuran 2 sampai $3 \mathrm{~cm}$ dan diinfestasikan ke lahan sebanyak 16 ekor per petakan lahan.

Setelah keong mas dimasukkan ke petakan lahan atraktan daun talas pun dimasukkan ke masing masing petakan sebanyak 500 gr. Pada setiap petakan lahan diletakkan atraktan daun talas sebanyak 500 gr, kemudian disekeliling atraktan ditaburkan 
bubuk moluskisida nabati sebanyak $130 \mathrm{gr}$ per petak lahan.

Peubah pengamatan yang dilakukan antara lain mortalitas keong mas, persentase rumpun terserang, waktu kematian dan faktor cuaca. Faktor cuaca yang diukur adalah curah hujan menggunakan alat Ombrometer $(\mathrm{mmHg})$, suhu udara dan kelembaban menggunakan Termo-hygro $\left({ }^{\circ} \mathrm{C}\right.$ dan \%) dan lama penyinaran menggunakan alat Lux meter $(\mathrm{mm})$. Hasil penelitian yang didapatkan dilakukan Uji T, Uji Significant dan Uji korelasi mengunakan SPSS versi 22.00 .

\section{HASIL DAN PEMBAHASAN}

\section{Mortalitas Keong Mas}

Dari hasil analisis sidik ragam menunjukkan bahwa pemberian serbuk nabati memberikan pengaruh nyata terhadap mortalitas keong mas untuk semua perlakuan. Hasil dari pengamatan persentase mortalitas keong mas dapat dilihat pada tabel 1. Pengambilan data dilakukan pada 1 HSA hingga 8 HSA. Dari hasil analisis sidik ragam menunjukkan bahwa pemberian serbuk nabati berpengaruh nyata terhadap mortalitas keong mas untuk semua perlakuan. Hal ini dapat dilihat pada lampiran.Pada Tabel 1 dapat diketahui bahwa pada perlakuan PO tidak terjadi kematian keong mas dari 1 HSA sampai 8 HSA terlihat dengan tingkat persentase mortalitasnya yang terendah. Pada pengamatan 2 HSA, perlakuan $\mathrm{P} 1$ sudah terdapat mortalitas keong mas berbeda dengan perlakuan P2, P3, P4, P5 dan kontrol. Pada pengamatan 7 HSA pada perlakuan P1 sudah menunjukkan persentase mortalitas keong mas $100 \%$ dengan kata lain mencapai mortalitas tertinggi sehingga perlakuan yang paling efektif adalah dengan menggunakan serbuk pinang. Hal ini dikarenakan serbuk nabati pinang mengandung senyawa yang toksisitasnya cukup tinggi terhadap keong mas. Hal ini membuktikan dalam penelitian sebelumnya Gassa (2011) yang menyatakan bahwa pinang mengandung senyawa alkaloid yaitu ester metal-tetrahidrometil-nikotinat yang berwujud minyak basa keras bersifat toksik menyebabkan kelumpuhan dan terhentinya pernafasan keong mas.

Dari hasil analisis menggunakan aplikasi SPSS versi 22.00 pada tabel 1 diperoleh pestisida nabati yang paling efektif adalah dengan menggunakan serbuk pinang (P1) dan yang kurang efektif dibanding pestisida lainnya adalah dengan menggunakan serbuk eceng gondok (P5). Hal ini juga terlihat bahwa persentase mortalitas berbanding lurus dengan persentase rumpun terserang. Semakin tinggi mortalitas maka semakin tinggi pula persentase rumpun terserang. Hal ini membuktikan dalam penelitian sebelumnya Jamal (2017) dan Massagumi dan Latif (2012) yang menyatakan bahwa semakin tinggi mortalitas dan efikasi yang disebabkan akibat pengaruh dari pestisida yang diberikan, maka semakin kecil pula kerusakan tanaman yang terjadi.

Dari Tabel 1 menunjukan bahwa pada pengamatan $3 \mathrm{HSA}$, perlakuan P2 berbeda dengan perlakuan P4 dan P0. Pada pengamatan 8 HSA pada perlakuan P2 sudah menunjukkan persentase mortalitas keong mas $100 \%$. Hal ini dikarenakan serai memiliki kandungan sitronela yaitu sebesar 35\%. Senyawa sitronella mempunyai sifat racun dehidrasi (Rusdy, 2010). Senyawa sitronela mempunyai sifat racun kontak yang dapat mengakibatkan kematian karena kehilangan cairan terus menerus. Tanaman ini dapat digunakan sebagai pengganti pestisida kimia.

Pada P3 serbuk daun sukun pada hari ke 3 sampai hari ke 8 berbeda dengan perlakuan P0. Kematian keong mas pada setiap harinya memang memiliki persentase yang rendah tapi pada hari ke 8 persentase mortalitas keong mas mencapai $100 \%$. Hal ini karena daun sukun juga mengandung saponin dan beberapa golongan senyawa seperti flavonoid, steroid, tanin, serta phenol Puspasari (2014). Gejala keracunan saponin pada keong mas, sesuai dengan penelitian sebelumnya yang menyatakan bahwa senyawa saponin dalam badan air membuat keong mas memproduksi lendir sehingga mengakibatkan proses pernapasan keong mas terhambat Francis et al., (2002) dan Manueke (2016).

Mortalitas keong mas pada perlakuan P4 serbuk mengkudu terjadi setelah 4 HSA. Pada saat pengamatan pada perlakuan P4 terdapat lendir berminyak yang keluar dari tubuh keong mas hal ini serbuk mengkudu bertindak sebagai racun perut. Mursito (2002), menyebutkan bahwa mengkudu mengandung minyak atsiri, alkaloid, saponin, flavonoid, polifenol dan antrakuinon. Kandungan lainnya adalah terpenoid, asam askorbat, scolopetin, serotonin, damnacanthal, resin, glikosida, eugenol dan proxeronin (Bangun \& Sarwono, 2005).

Dari hasil pengamatan pada 1 HSA sampai 3 HSA perlakuan P5 serbuk daun eceng gondok belum menimbulkan pengaruh yang mematikan terhadap keong mas. Kematian keong mas baru tampak pada 4 HSA. Pada pengamatan selanjutnya meningkat meskipun dengan laju peningkatannya sangat rendah dan pada 8 
HSA mortalitas keong mas mencapai $100 \%$. Eceng gondok merupakan salah satu tumbuhan yang mengandung tanin (penyamak nabati) terutama pada bagian daunnya. Johnly dan Suryanto (2010), telah melakukan penelitian untuk menentukan kandungan fenolik, flavonoid, dan tanin pada eceng gondok. Hasil menyebutkan bahwa total fenolik daun eceng gondok $26,327 \mathrm{mg} / \mathrm{kg}$, batang 600 $\mathrm{mg} / \mathrm{kg}$, akar $1300 \mathrm{mg} / \mathrm{kg}$. Total flavonoid daun eceng gondok $3,3 \mathrm{mg} / \mathrm{kg}$, batang $1,0 \mathrm{mg} / \mathrm{kg}$, akar $1,3 \mathrm{mg} / \mathrm{kg}$. Total tanin daun eceng gondok 25,300 mg/kg, batang $300 \mathrm{mg} / \mathrm{kg}$, akar 1400 $\mathrm{mg} / \mathrm{kg}$.

Tabel 1. Persentase mortalitas keong mas P. canaliculata untuk setiap perlakuan.

\begin{tabular}{|c|c|c|c|c|c|c|c|c|}
\hline \multirow[t]{2}{*}{ Perlakuan } & \multicolumn{8}{|c|}{ Data Pengamatan (\%) } \\
\hline & I & II & III & IV & $\mathrm{V}$ & $\mathrm{VI}$ & VII & VIII \\
\hline POU1 & 0 & 0 & 0 & 0 & 0 & 0 & 0 & 0 \\
\hline POU2 & 0 & 0 & 0 & 0 & 0 & 0 & 0 & 0 \\
\hline POU3 & 0 & 0 & 0 & 0 & 0 & 0 & 0 & 0 \\
\hline POU4 & 0 & 0 & 0 & 0 & 0 & 0 & 0 & 0 \\
\hline P1U1 & 0 & 0 & 0,06 & 0,56 & 0,31 & 0 & 0,06 & 0 \\
\hline P1U2 & 0 & 0 & 0,18 & 0,62 & 0,18 & 0 & 0 & 0 \\
\hline P1U3 & 0 & 0,06 & 0,06 & 0,25 & 0,37 & 0,25 & 0 & 0 \\
\hline P1U4 & 0 & 0 & 0 & 0,56 & 0,25 & 0,18 & 0 & 0 \\
\hline P2U1 & 0 & 0 & 0,06 & 0,25 & 0,37 & 0,12 & 0,18 & 0 \\
\hline P2U2 & 0 & 0 & 0 & 0,37 & 0,37 & 0 & 0,25 & 0 \\
\hline P2U3 & 0 & 0 & 0,12 & 0,43 & 0,06 & 0,25 & 0 & 0,12 \\
\hline P2U4 & 0 & 0 & 0 & 0,12 & 0,18 & 0,37 & 0,06 & 0,25 \\
\hline P3U1 & 0 & 0 & 0 & 0,37 & 0,12 & 0,06 & 0,31 & 0,12 \\
\hline P3U2 & 0 & 0 & 0 & 0,18 & 0,25 & 0,25 & 0,12 & 0,18 \\
\hline P3U3 & 0 & 0 & 0,06 & 0,12 & 0,25 & 0,5 & 0 & 0,06 \\
\hline P3U4 & 0 & 0 & 0 & 0,25 & 0,18 & 0,43 & 0,12 & 0 \\
\hline P4U1 & 0 & 0 & 0 & 0.12 & 0,25 & 0,43 & 0 & 0,18 \\
\hline P4U2 & 0 & 0 & 0 & 0,31 & 0,12 & 0,37 & 0,06 & 0,12 \\
\hline P4U3 & 0 & 0 & 0 & 0,31 & 0,12 & 0,12 & 0,12 & 0,31 \\
\hline P4U4 & 0 & 0 & 0 & 0,25 & 0,06 & 0,25 & 0,31 & 0,12 \\
\hline P5U1 & 0 & 0 & 0 & 0 & 0,18 & 0,37 & 0,31 & 0,12 \\
\hline P5U2 & 0 & 0 & 0 & 0,12 & 0,06 & 0,25 & 0,5 & 0,06 \\
\hline P5U3 & 0 & 0 & 0 & 0,06 & 0,18 & 0,31 & 0,43 & 0,06 \\
\hline P5U4 & 0 & 0 & 0 & 0,43 & 0,12 & 0,25 & 0,18 & 0 \\
\hline
\end{tabular}

\section{Persentase Rumpun Terserang}

Dari hasil sidik ragamnya menunjukkan pada perlakuan pemberian serbuk nabati berpengaruh nyata terhadap persentase rumpun terserang. Dari Tabel 2 menunjukkan bahwa pada perlakuan P1, P2, $\mathrm{P} 3, \mathrm{P} 4$, dan $\mathrm{P} 5$ persentase rumpun terserang berbeda nyata dengan perlakuan P0. Pada perlakuan P1, P2, P3, dan P4 persentase rumpun terserang dibawah $1 \%$ dikarenakan serbuk nabati dapat mengendalikan hama keong mas dengan tingkat mortalitas yang tinggi sedangkan pada perlakuan P0 persentase rumpun terserang $14,66 \%$. Hal ini kembali dibuktikan dengan tingkat populasi keong mas yang sangat berpengaruh terhadap kerusakan tanaman padi. Populasi hama keong mas yang rendah atau dikendalikan, maka tanaman padi tidak mengalami kerusakan yang parah (Susetyo et al., 2008).

Waktu kematian keong mas tercepat terdapat pada perlakuan P1 pada 2 hsa sedangkan waktu kematian keong mas paling lama terdapat pada perlakuan P4 dan P5.
Perlakuan P2 dan P3 persentase kematian keong mas tertinggi pada hari ke 6 dan 7. Hal ini dikarenakan cangkang keong mas yang keras dan sering menutup diri sehingga pestisida nabati tidak sampai ke permukaan kulit keong mas dan dikarenakan kurang banyaknya konsentrasi yang diberikan.

Tabel 2. Persentase rumpun terserang dan waktu kematian untuk setiap perlakuan (\%)

\begin{tabular}{ccc}
\hline Perlakuan & $\begin{array}{c}\text { Persentase } \\
\text { Rumpun } \\
\text { Terserang }\end{array}$ & $\begin{array}{c}\text { Waktu } \\
\text { Kematian } \\
\text { HSA }\end{array}$ \\
\hline P0 & $0,549^{*}$ & 0 \\
P1 & 0,062 & 2 \\
P2 & 0,155 & 3 \\
P3 & 0,186 & 3 \\
P4 & 0,216 & 4 \\
P5 & 0,185 & 4 \\
\hline
\end{tabular}

Keterangan : Angka yang diikuti oleh tanda * menunjukkan berbeda nyata dengan perlakuan lainnya menurut uji Tukey pada taraf $5 \%$ dengan nilai $F=23,023$ pada nilai $P<0,005$ 
Racun yang terkandung dalam ekstrak daun sukun dapat dengan cepat terserap melalui permukaan kulit, melumpuhkan urat syaraf dan menyebabkan kematian dengan segera (Ardiansyah et al., 2002). Semakin tinggi konsentrasi yang digunakan maka semakin cepat serangga mati. Hal ini sesuai dengan Laoh et al. (2013) yang menyatakan bahwa pemberian konsentrasi yang semakin tinggi, maka semakin cepat serangga mati, dikarenakan semakin banyak zat aktif yang masuk/terkena pada hama.

Penggunaan atraktan daun talas pada penelitian membantu efektifitas pestisida nabati yang diaplikasikan. Atraktan daun talas menarik keong mas sehingga keong mas berkumpul dan memakan daun talas sehingga ketika keong mas memakan daun talas yang diatasnya sudah ditaburi dengan pestisida nabati akan mengalami reaksi. Hal ini didukung oleh penelitian Tombuku et.al., (2013) and Khobkul and Ana (2015) yang mengatakan ketertarikan Keong mas terhadap daun talas di duga karena terdapat kandungan kimia yang bersifat atraktan dibandingkan dengan daun tanaman lainnya. Talas mengandung senyawa kimia yang dihasilkan dari metabolisme sekunder diantaranya mengandung pati yang mudah dicerna sebanyak $18,2 \%$.

\section{Faktor Cuaca}

Tabel 3 diatas menunjukkan Uji Korelasi hubungan penggunaan pestisida nabati dengan faktor lingkungan. Berdasarkan hasil pengukuran faktor lingkungan (suhu, kelembapan,curah hujan dan lama penyinaran) dapat diketahui bahwa hubungan antara faktor lingkungan kelembapan dengan persentase mortalitas keong mas dengan nilai Pearson Corelation $\left(-0,172^{\star}\right)$. Dalam hal ini semakin tinggi kelembapan semakin rendah persentase mortalitas keong mas dan sebaliknya. Hal ini sesuai dengan literatur Cowie (2006) yang mengatakan bahwa faktor-faktor lingkungan seperti luasan habitat, variasi cuaca, kondisi air, kepadatan populasi keong mempengaruhi kecepatan tumbuh hewan ini.

Tabel 3. Uji Korelasi hubungan penggunaan pestisida nabati dengan faktor lingkungan.

\begin{tabular}{|c|c|c|c|c|c|c|c|}
\hline & & $\%$ Mortalitas & $\begin{array}{l}\text { \% Rumpun } \\
\text { Terserang }\end{array}$ & Suhu & $\begin{array}{l}\text { Kelem } \\
\text { bapan }\end{array}$ & $\begin{array}{l}\text { Curah } \\
\text { Hujan }\end{array}$ & $\begin{array}{c}\text { Lama } \\
\text { Penyinaran }\end{array}$ \\
\hline \multirow[t]{2}{*}{$\%$ Mortalitas } & Pearson & 1 & & & & & \\
\hline & $\underset{N}{\text { Correlation Sig (2-tailed) }}$ & $\begin{array}{c}0 \\
192\end{array}$ & & & & & \\
\hline \multirow{3}{*}{$\begin{array}{l}\text { \% Rumpun } \\
\text { Terserang }\end{array}$} & Pearson & $-0,389^{* *}$ & 1 & & & & \\
\hline & Correlation Sig (2-tailed) & 0 & & & & & \\
\hline & $\mathrm{N}$ & 192 & 192 & & & & \\
\hline \multirow[t]{3}{*}{ Suhu } & Pearson & $-0,147$ & 0,094 & 1 & & & \\
\hline & Correlation Sig (2-tailed) & 0,08 & 0,263 & & & & \\
\hline & $\mathrm{N}$ & 143 & 143 & 143 & & & \\
\hline \multirow[t]{2}{*}{ Kelembapan } & Pearson & $-0,172^{*}$ & 0,144 & $0,90^{\star \star}$ & 1 & & \\
\hline & Correlation Sig (2 tailed) & $\begin{array}{l}0,04 \\
143\end{array}$ & 0,087 & $\begin{array}{c}0 \\
143\end{array}$ & 143 & & \\
\hline \multirow[t]{2}{*}{ Curah Hujan } & Pearson & $-0,092$ & 0,05 & $-0,03$ & 0,122 & 1 & \\
\hline & $\underset{N}{\text { Correlation Sig }}$ (2-tailed) & $\begin{array}{c}0,247 \\
143\end{array}$ & $\begin{array}{l}0,555 \\
143\end{array}$ & $\begin{array}{l}0,72 \\
143\end{array}$ & $\begin{array}{c}0,148 \\
143\end{array}$ & 143 & \\
\hline \multirow{3}{*}{$\begin{array}{c}\text { Lama } \\
\text { Penyinaran }\end{array}$} & Pearson & 0,023 & $-0,025$ & $-0,08$ & $-0,244$ & $-0,17$ & 1 \\
\hline & Correlation Sig (2-tailed) & 0,786 & 0,764 & 0,315 & 0,003 & 0,041 & \\
\hline & $\mathrm{N}$ & 143 & 143 & 143 & 143 & 143 & 143 \\
\hline
\end{tabular}

\section{KESIMPULAN DAN SARAN}

Semua perlakuan moluskisida nabati yang diuji dapat mengendalikan keong mas. Serbuk pinang dapat digunakan sebagai moluskisida nabati yang efektif untuk mengendalikan keong mas dengan persentase mortalitas $100 \%$ dan mampu mencegah kerusakan rumpun tanaman padi.

\section{DAFTAR PUSTAKA}

Budiarsih, S.K. 2011. Makalah Program PPM Pemanfaatan Beberapa Tanaman yang Berpotensi Sebagai Bahan Anti Nyamuk. Yogyakarta: UNJ.

BPS Sumatera Utara. 2015. Produksi Padi dan Palawija Sumatera Utara (Angka 
Tetap Tahun 2014). Berita Resmi Statistik. Sumatera Utara.

Cowie, R. H. 2006. Apples Snail as Agricultural Pests, their Biology, Impact, and Management. Project Summary. USA: Bishop Museum.

Francis G, Kerem Z, Makkar HPS, Bekker K. 2002. The biological action of saponins in animal systems.British Journal of Nutrition 88: 587-605.

Gassa A. 2011. Pengaruh Buah Pinang (Areca catechu) terhadap Mortalitas Keong Mas (Pomacea canaliculata) pada Berbagai Stadia. Universitas Hasanudin. Makassar. J. Fitomedika. 7 (3), 171-174.

Hutasoit, R.T. 2012. Uji Beberapa Varietas Tanaman Padi (Oryza sativa. L.) terhadap Hama Keong Mas (Pomaceae canaliculata Lamarck) (Mollusca ; Ampullariidae). Skripsi. Fakultas Pertanian. Universitas Andalas. Padang.

Johnly, A. R. dan E. Suryanto. 2010. Analisis Fitokimia Enceng Gondok (Eichornia crassipes) dan Efeknya sebagai Agen Photoreduksi Fe3+. Jurnal. Fakultas Matematika dan IImu Pengetahuan Alam, Universitas Sam Ratulangi, Manado.

Khobkul Nongnutch and Ana Jakkahpun Nanuam. 2015. Alternative Biopesticide for Golden Apple Snail. Suranaree J. Sci. Technol.23 (1): 14.

Laoh, H., Rustam, R. dan Permana, R. 2013. Pemberian Beberapa Dosis Tepung Biji Pinang (Areca catechu L.) Lokal Riau untuk Mengendalikan Hama Keong Emas (Pomacea canaliculata L.) pada Tanaman Padi. 1 (2):1-7.

Manueke J. 2016. Pengendalian Hama Keong Emas (Pomacea canaliculata Lamarck) Pada Tanaman Padi Sawah Dengan Menggunakan Ekstrak Buah Bitung (Barringtonia asiatica L.). Jurnal LPPM Bidang Sains dan Teknologi Volume 3 Nomor 1. Manado.
Massaguni, R and Latif, S.N.H.M. 2012. Neem crude extract and potensial biopesticide for controlling golden apple snail, Pomacea canaliculata. In Pesticides. Advancesin chemical and botanical pesticides (Soundarajan, R.P.eds.): 233-254. InTech, Rijeka, Croatia.

Mursito, B. 2002. Ramuan Tradisional untuk Pengobatan Jantung. Penebar Swadaya. Jakarta.

Puspasari RK. 2014. Studi Aktivitas Antibakteri dari Ekstrak Daun Sukun (Artocarpus altilis) Terhadap Pertumbuhan Bakteri Pseudomonas aeruginosa [skripsi]. Bandung (ID): Universitas Pendidikan Indonesia.

Roja, A. 2009. Pengendalian Hama dan Penyakit Secara Terpadu (PHT) pada Padi Sawah. Balai Pengkajian Teknologi Pertanian Sumatera Barat.

Rusdy, A. 2010. "Pengaruh Pemberian Ekstrak Bawang Putih Terhadap Mortalitas Keong Mas". Jurnal.J.Floratek 5: 172-180. Unsyiah Banda Aceh.

Suharto, H dan N. Kurniawati. 2009. "Keong mas dari hewan peliharaan menjadi hama utama padi sawah ". Balai Besar Penelitian Tanaman Padi.

Susetyo, T., Ruswandi. dan Etty, P. 2008. Tekhnologi Pengendalian Organisme Pengganggu Tanaman (OPT) Ramah Lingkungan. Direktorat Perlindungan Pangan. Jakarta

Ng, T.H. and Tan, S.K. 2011.Observation of land snail feeding on the eggs of Pomacea canaliculata (Lammarck, 1822) (Mollusca: Gastropoda). Nature in Singapore 4:79-83.

Trisnadi R. 2016. Pestisida Nabati Ramah Lingkungan untuk Mengendalikan Hama dan Penyakit Tanaman. Dinas Perkebunan dan Kehutanan. Pemerintah Kabupaten Probolinggo. Probolinggo.

Utama, M.Z.H., W.Haryoko, R. Munir dan Sunadi. 2009. Penapisan Varietas Padi Toleran Salinitas pada Lahan Rawa di Kabupaten Pesisir Selatan. J.Agron. Ind. 37 (2) :101-106. 